\title{
Prevalence and factors associated with erectile dysfunction among adult men in Moshi municipal, Tanzania: community- based study
}

Kenan B. Nyalile ${ }^{1 *+}$, Emmanuel H. P. Mushi ${ }^{1+}$, Epiphania Moshi ${ }^{1 \dagger}$, Beatrice J. Leyaro ${ }^{2}$, Sia E. Msuya ${ }^{1,2,3 \dagger}$ and Orgeness Mbwambo ${ }^{4+}$

\begin{abstract}
Background: Erectile dysfunction (ED) has a negative impact on ones' relationships with poor quality of life as inevitable result. The effects of ED maybe worse in developing countries setting like Tanzania because men's sexual health has been forgotten. Men's sexual and reproductive health needs are not in the national reproductive health strategic. This study aimed to determine the prevalence and factors associated with erectile dysfunction among adult men in Moshi municipality, northern Tanzania.

Results: The mean age of the 381 men was 39.6 (SD \pm 16.8 ) years. The overall prevalence of ED on this study was 29.7\%. The severity of ED among study participants was; $13.4 \%$ (51), 9.7\% (37), 3.7\% (14), 2.9\% (11) had mild, mild to moderate, moderate and severe erectile dysfunction respectively. Age 40-54 years (Adjusted OR 5.0, 95\% Cl 2.5-9.9), $\geq 55$ years (aOR 11.7, 95\% Cl 5.8-23.7) and hypertension ( $\mathrm{aOR} 2.6,95 \% \mathrm{Cl}$ 1.1-6.4) were independent predictors of $\overline{E D}$ respectively.

Conclusion: The prevalence of ED is high among men in Moshi municipal as 1 out of 3 men have ED. Age and hypertension were independent predictors of ED. These results point to the need of community awareness and education programs to raise awareness among men about existence of ED problem, its consequence and where they can get advice and care in this setting. Further, health providers taking care of hypertensive and men with DM should be equipped with knowledge and skills on early detection for ED and how to counsel and where to refer patients for help.
\end{abstract}

Keywords: Erectile dysfunction, Diabetes mellitus, Hypertension, Physical activities, Prevalence, Predictors, Tanzania

\footnotetext{
* Correspondence: kenanbosco@gmail.com

${ }^{\dagger}$ Kenan B Nyalile, Emmanuel HP Mushi and Epiphania Moshi are equal authorship

${ }^{\dagger}$ Sia E Msuya and Orgeness Mbwambo are equal mentorship

${ }^{1}$ Institute of Public Health, Department of Community Health, Kilimanjaro Christian Medical University College (KCMUCo), Po Box 2240, Moshi, Tanzania Full list of author information is available at the end of the article
}

(c) The Author(s). 2020 Open Access This article is licensed under a Creative Commons Attribution 4.0 International License, which permits use, sharing, adaptation, distribution and reproduction in any medium or format, as long as you give appropriate credit to the original author(s) and the source, provide a link to the Creative Commons licence, and indicate if changes were made. The images or other third party material in this article are included in the article's Creative Commons licence, unless indicated otherwise in a credit line to the material. If material is not included in the article's Creative Commons licence and your intended use is not permitted by statutory regulation or exceeds the permitted use, you will need to obtain permission directly from the copyright holder. To view a copy of this licence, visit http://creativecommons.org/licenses/by/4.0/ The Creative Commons Public Domain Dedication waiver (http://creativecommons.org/publicdomain/zero/1.0/) applies to the data made available in this article, unless otherwise stated in a credit line to the data. 


\section{Résumé}

Contexte: La dysfonction érectile (DE) a un impact négatif sur les relations, avec une qualité de vie moindre comme résultat inévitable. Les effets de la DE peuvent être pire dans les pays en développement comme la Tanzanie parce que la santé sexuelle des hommes a été oubliée. Les besoins des hommes en matière de santé sexuelle et reproductive ne sont pas inclus dans le cadre de la stratégie nationale en matière de santé reproductive. Cette étude avait pour objectif de déterminer la prévalence et les facteurs associés à la dysfonction érectile chez les hommes adultes dans la municipalité de Moshi, dans le nord de la Tanzanie.

Résultats: L'âge moyen des 381 hommes était de 39,6 ans (SD 16,8). La prévalence globale de la DE dans cette étude était de 29,7\%. La sévérité de la DE chez les participants à l'étude a été comme suit: 13.4\% (51) avaient une dysfonction érectile légère, 9,7\% (37) une DE légère à modérée, 3,7\% (14) une DE modérée, et 2,9\% (11) sévère. Les facteurs de prédiction indépendants de la DE étaient respectivement un âge entre 40-54 ans (OR ajusté $=5,0$; IC $95 \%$ 2,5-9,9), un âge $>55$ ans (OR ajusté $=11,7 ;$ IC 95\% 5,8-23,7), et la présence d'une hypertension (OR ajusté $=2,6$; IC 95\% 1,1-6,4).

Conclusions: II existe une prévalence élevée de la DE chez les hommes dans la municipalité de Moshi, avec 1 homme sur 3 qui présente une DE. L'âge et l'hypertension étaient des facteurs de prédiction indépendants de la $D E$. Ces résultats indiquent un besoin de programmes de sensibilisation et d'éducation communautaires pour sensibiliser les hommes à l'existence d'un problème de DE, de ses conséquences et des lieus où ils peuvent obtenir des conseils et des soins dans ce cadre. En outre, les prestataires de soins de santé qui s'occupent d'hommes hypertendus ou d'hommes atteints de diabète sucré devraient avoir des connaissances et des compétences sur la détection précoce de la DE, sur la façon de conseiller ces hommes et de les informer des lieux où ils peuvent trouver de l'aide.

Mots-clés: Dysfonction érectile, Diabète sucré, Hypertension, Activités physiques, Prévalence, Facteurs prédictifs, Tanzanie

\section{Background}

Erectile dysfunction (ED) is defined as the persistence inability to achieve and maintain an erection adequate to permit satisfactory sexual act [1]. Though considered by many to be part of normal aging process, ED can be an outcome of several causes. ED has been found to be more prevalent among aged population [2], smokers [3] and in population with comorbidities like diabetes mellitus [4], peripheral vascular disorders, coronary artery disease [5] and among individuals with hypertension [6]. Psychogenic illness like anxiety [7], and depression [8] have also shown an impact on ED.

In Africa, few epidemiological studies have been conducted concerning the burden of erectile dysfunction. Studies of ED in Africa have been done both at community and hospital settings. The prevalence of ED in a population-based study in Egypt was 10\% for moderate and $13 \%$ for severe ED, while in Ghana a study among men aged 19 years or more in a population reported prevalence of $65.9 \%[3,9]$. In Nigeria the prevalence of ED ranged from $43.8-58.9 \%$ in a community-based setting $[2,10]$, without much difference $(41.5-65.8 \%)$ with ED prevalence among men attending hospitals for diabetic, hypertension or outpatient care $[6,11]$. In Tanzania a study in Dar es Salaam, showed ED prevalence of 24 and 55\% among men in a community-setting and those attending at diabetic care respectively $[4,12]$.
Nearly all the studies used men aged 18 years and above and cross-section design.

ED has a negative impact on men's health. Poor quality of life has been described in men with ED. Negative consequence on men's mental health like depression, anxiety and low self-esteem have also been reported [8, 13]. The effects of ED maybe worse in developing countries setting like Tanzania because men's sexual health has been forgotten. Men's sexual and reproductive health needs are not in the national reproductive health strategic plans [14]. Studies have shown an association between ED with advanced age, smoking, and presence of hypertension and diabetes [3, 10, 12]. Given differences on ED prevalence within the same country, maybe due to differences in background occurrence of comorbidities like diabetes and hypertension among men, there is a need to have information from different settings and population to understand the burden of the problem. This community-based study was conducted to determine the prevalence and factors associated with ED in an urban setting in northern Tanzania.

\section{Methods}

\section{Study design and site}

The study was a community- based cross sectional study. Recruitment and data collection were conducted 
in July 2019, at Moshi Municipal, situated in Kilimanjaro region in the northern Tanzania.

Kilimanjaro is one of the 31 regions found in northern zone of Tanzania. It is the home of 1.64 million people according to 2012 census. Moshi municipal is one of the seven district of Kilimanjaro region. It has 21 wards and covers an area of $59 \mathrm{~km}^{2}$. The municipal has a population of 184,292 where males are 89,174 and females are 95,118 according to 2012 census.

\section{Study population, sampling and data collection procedures Population}

The study population was men aged at least 18 years in selected wards of Moshi Municipal and consented to participate in the study. The study excluded men who are not permanent residents in the study area.

\section{Sample size}

Sample size for this study was estimated by using the formula for precision

$$
\mathrm{N}=\mathrm{Z}^{2} \mathrm{p}(1-\mathrm{p}) / \varepsilon^{2}
$$

Where $N$ is estimated minimum sample size; $Z$ is confidence level at $95 \%$ (standard value is 1.96); $\boldsymbol{P}$ is proportion of ED in population based on study by Pallangyo et al., where the prevalence of ED was $24 \%$ [12] and $\boldsymbol{\varepsilon}$ is precision at $95 \% \mathrm{CI}=0.05$.

The minimum sample that was required for this study was 346 men. Addition of $10 \%$ for non-response gave a minimum sample of 381 men aged at least 18 years.

\section{Sampling}

Multistage sampling technique was used to obtain men who participated in the study. The multistage sampling techniques involved the following stages. Stage 1: 4 out of 21 wards that make up the municipal were randomly selected. Stage 2: Two streets from each of the selected ward were randomly selected: At Majengo ward, Shauri moyo and Sokoni streets, were randomly selected. At Mji Mpya ward, Sokoni and Langoni streets were randomly selected. At Kiboriloni ward, mnazi mmoja and Kilimanjaro District Council (KDC) streets were randomly selected. At Rau ward, Saba saba and Karikacha streets were randomly selected. From these streets, men aged 18 years and above who consented to participate in this study were recruited.

\section{Study procedures}

Ethical clearance was obtained from the Kilimanjaro Christian Medical University College (KCMUCo) Ethical committee before starting the research. The ethical clearance was delivered to District Medical Officer
(DMO) of Moshi Municipal, where permission to conduct the study was sought from the DMO office. DMO gave us introductory letter that was presented to Ward and streets leaders. The ward and street leaders were all informed about their key role of introducing researchers to the community and help to inform adult males about the study prior to the beginning of the study.

After reaching to the center which was established, at respective wards those who were eligible and consented to participate were interviewed. The interviews were conducted by three medical students who were in their 4th year of training and have rotated in the urology department for four weeks. They underwent training by the consultant urologist (OM) for 3 days before commencement of data collection. This was followed by general clinical examination and measurement of the blood pressure (BP), anthropometric measurements and taking blood for Random blood glucose level (RBG) measurement. The interviews and clinical examination were conducted in private room which was either a ward executive officer office or room at a local clinic. After the test participants were informed the results of $\mathrm{BP}$, overweight/obesity and RBG on the same day.

Those found with confirmed either diabetes or hypertension were informed about their results and then referred to the nearby health centre. Those with erectile dysfunction were referred at KCMC referral hospital urology clinic where there is expertise to manage the condition. The physician responsible was then informed about their health status through a referral letter. They were also given advice on diet, physical activity, on salt and alcohol intake.

\section{Data collection tool and methods Data collection tools}

Data was collected using a questionnaire which had both open and closed ended questions and was in Swahili language. The questionnaire had three sections, the first part collected information on socio-demographic characteristics, and the second part assessed the behavioural characteristics of the participant. The third part was clinical examination. The validated Swahili-translated 5item version of the international index of erectile function (IIEF-5) scale was used to assess erectile dysfunction.

\section{Data collection methods}

Face to face interview was used to collect information from the consented participant. Blood pressure was measured twice before and after the interview. Weight $(\mathrm{kg})$, height $(\mathrm{cm})$, blood sample (finger prick) was collected to check for random blood glucose (RBG). Data collection process took place privately in a selected room (i.e. ward executive office). 


\section{Anthropometric measurement}

Weight in $\mathrm{kg}$ was measured using weighing machine (SECA brand) participants were requested to remove shoes, extra clothing like jackets and anything in pockets before measurements. Height was measured with a height stadiometer where by individual stood upright with no shoes and the ruler hook was placed such that it just touches the head then the height in $\mathrm{cm}$ was recorded. Body Mass Index (BMI) was calculated by a ratio of weight (in kilograms) to height (in meters) squared. BMI cut-off values of World Health Organization (WHO) were used.

\section{Blood pressure measurements}

Blood pressure was measured by manual BP machines. $\mathrm{BP}$ was recorded from the left arm using an appropriate size cuff that covers two - third of the upper arm after the participant rested for at least five minutes and no smoking or caffeine 30 min before measurements, with the arm supported at the level of the heart, palm facing upward. Two measurement were taken at the start of interview and at the end in a sitting position while the participant rested quietly, then the average of the two measurement was recorded.

\section{Blood glucose measurements}

Random Blood glucose was measured using a blood glucose monitor (GlucoPlus brand). Blood sample was collected through finger pricking and dropped on glucometer strip to give the reading.

\section{Data analysis}

The data was entered and analysed using SPSS 20. Before analysis, data was cleaned by running frequency of each variable. Categorical variables were summarized into frequency and percent while continuous variables were summarized using measures of central tendency and their respective measure of dispersion. Odds ratio with their 95\% confidence interval were used to measure the strength of association between age, alcohol drinking, tobacco use, physical activities, overweight/obesity, hypertension, diabetes mellitus and erectile dysfunction. Multivariable logistic regression analysis was conducted to control for confounders and get independent predictors for erectile dysfunction. $P$-value of $<0.05$ was considered statistically significant.

\section{Categorization of variables}

ED was assessed using IIEF with 5 questions each with scale of 5. Maximum possible score is 25 and minimum score is 5 . The IIEF-5 scale categorizes ED into five categories depending on the score i.e. 22-25: no ED, 17-21: mild ED, 12-16: mild to moderate ED, 8-11: moderate, 5-7: severe ED.
A systolic blood pressure (SBP) $<120 \mathrm{mmHg}$ and a diastolic blood pressure (DBP) $<80 \mathrm{mmHg}$ was defined as normotensive. Pre- hypertension was defined as SBP of $120-139 \mathrm{mmHg}$ or DBP of $80-89 \mathrm{mmHg}$, while SBP $\geq 140 \mathrm{mmHg}$ or DBP $\geq 90 \mathrm{mmHg}$ indicated hypertension.

Diabetes was defined as RBG $\geq 11.1 \mathrm{mmol} / \mathrm{L}$. Prediabetes was defined as RBG of $7.8-11.0 \mathrm{mmol} / \mathrm{L}$.

WHO BMI cut-off values were used. Underweight was defined as BMI of $<18.5 \mathrm{Kg} / \mathrm{m}^{2}$, normal was defined as BMI of $18.5-24.9 \mathrm{Kg} / \mathrm{m}^{2}$, overweight was defined as BMI of $25-29.9 \mathrm{Kg} / \mathrm{m}^{2}$ and obese was defined as BMI of $\geq 30 \mathrm{Kg} / \mathrm{m}^{2}$.

Physical inactivity was defined as having less than 150 min of moderate to vigorous -intensity physical activity throughout the week.

\section{Results}

Socio-demographic, life style and clinical characteristics of participants

A total of 390 men aged 18 years and above were approached and 381 (97.7\%) agreed to participate in the study. The age of the participants ranged from 18 to 87 years with mean age of $39.6( \pm 16.8)$ years. Of the 381 participants; $61.2 \%$ were married/cohabiting, $52.0 \%$ had secondary education or higher, $49 \%$ reported to be taking alcohol, $22.0 \%$ were smoking cigarette and 36\% had $\leq 150 \mathrm{~min}$ of moderate to vigorous intensity physical activities per week, Table 1.

The mean BMI was $24.4( \pm 10.3) \mathrm{kg} / \mathrm{m}^{2}$ and $36.2 \%$ were overweight and obese. The mean SBP and DBP were $122( \pm 29) \mathrm{mmHg}$ and $77( \pm 10) \mathrm{mmHg}$ respectively and $12.3 \%$ of the participants had high blood pressure. The mean random blood glucose level was $5.9( \pm 1.5)$ $\mathrm{mmol} / \mathrm{L}$ and $2.1 \%$ of the 381 men had diabetes mellitus (Table 1).

\section{Prevalence and factors associated with erectile dysfunction(ED)}

The overall prevalence of erectile dysfunction among adult males in Moshi municipal was $29.7 \%(n=113)$. Of the 113 men with ED, $45.3 \%$ (51) had mild form, 32.7\% (37) had mild to moderate form, $12.3 \%$ (14) had moderate form and $9.7 \%$ (11) had severe form.

In bivariate analysis, age, alcohol use, overweight and obesity, high blood pressure and pre-diabetes/diabetes were associated with erectile dysfunction (Table 2). Participants aged 40-54 and $\geq 55$ had 6.6 and 16.0 higher odds of having ED compared to participants aged 18-39. Men who were overweight had $90 \%$ higher odds of ED and obese had 2-fold odds of ED compared to men with normal BMI. Pre-hypertensive and hypertensive men had $80 \%$ higher odds of ED than to normotensive men and men with pre diabetes/ diabetes had 5-fold higher odds of ED than men with normal values. 
Table 1 Socio-demographic, life style and clinical characteristics of study participants $(N=381)$

\begin{tabular}{ll}
\hline Characteristic & Frequency \\
\hline Age group (years) & \\
$18-39$ & 227 \\
$40-54$ & 67 \\
$\geq 55$ & 87
\end{tabular}

Education level

No formal education 8

primary education 175

Secondary education/high 198

Marital status

Single

Married/cohabiting

Divorced/widower

\section{Alcohol intake}

Yes

No

Tobacco use

Yes

No

\section{4}

Physical activities

None

$<150 \mathrm{~min} /$ week

71

$\geq 150 \mathrm{~min} /$ week

65

Body mass index $\left(\mathrm{kg} / \mathrm{m}^{2}\right)$

Normal $^{a}$

Underweight $^{\mathrm{b}}$

28

Overweight ${ }^{c}$

Obesity $^{\text {d }}$

Blood pressure $(\mathrm{mmHg})$

Normal ${ }^{x}$

Pre-hypertensive ${ }^{y}$

88

Hypertension $^{z}$

47

Blood sugar level (mmol/L)

Normal $^{k}$

Pre diabetes'

Diabetes $^{\mathrm{m}}$

a $18.5-24.9 \mathrm{~kg} / \mathrm{m}^{2},{ }^{\text {b }}<18.5 \mathrm{~kg} / \mathrm{m}^{2 \mathrm{c}}, 25-29.9 \mathrm{~kg} / \mathrm{m}^{2 \mathrm{~d}} \geq 30 \mathrm{~kg} / \mathrm{m}^{2}$

${ }^{x}<120 / 80 \mathrm{mmHg}^{\text {y }} 120-139 / 89-89 \mathrm{mmHg}^{\mathrm{z}} \geq 140 / \geq 90 \mathrm{mmHg}$

${ }^{k}<7.8 \mathrm{mmol} / \mathrm{L}^{1} 7.8-11 \mathrm{mmol} / \mathrm{L}^{\mathrm{m}} \geq 11.1 \mathrm{mmol} / \mathrm{L}$

In multivariable logistic regression analysis, age and high blood pressure remained associated with ED. Men aged 40-54 years and those $55+$ had 5.0 and 11.7 significantly higher odds of ED than men aged 18-39 years. Likewise, men who were hypertensive had 2.6 higher odds of having ED than those who had normal blood pressure, Table 2.
Table 2 bivariate and multivariable logistic regression model for factors associated with erectile dysfunction $(N=381)$

\begin{tabular}{|c|c|c|c|}
\hline Variable & $\begin{array}{l}E D=113 \\
n(\%)\end{array}$ & COR $(95 \% \mathrm{Cl})$ & aOR $(95 \% \mathrm{Cl})$ \\
\hline \multicolumn{4}{|l|}{ Age (years) } \\
\hline $18-39$ & $25(11.0)$ & 1 & \\
\hline $40-54$ & $30(44.8)$ & $6.6(3.5-12.4)$ & $5.0(2.5-9.9)^{*}$ \\
\hline$\geq 55$ & $58(66.7)$ & $16(8.8-29.7)$ & $11.7(5.8-23.7)^{*}$ \\
\hline \multicolumn{4}{|l|}{ Alcohol intake } \\
\hline No & $55(28.1)$ & 1 & \\
\hline Yes & $58(31.8)$ & $1.2(0.8-1.8)$ & \\
\hline \multicolumn{4}{|l|}{ Tobacco use } \\
\hline No & $80(27.1)$ & 1 & \\
\hline Yes & $33(38.4)$ & $1.7(1-2.8)$ & $1.5(0.8-2.9)$ \\
\hline \multicolumn{4}{|l|}{ Physical activity } \\
\hline$\geq 150 \mathrm{~min} /$ week & $69(28.2)$ & 1 & \\
\hline None/< 150 min/week & $44(32.4)$ & $1.2(0.8-1.9)$ & \\
\hline \multicolumn{4}{|l|}{ Body mass index $\left(\mathrm{kg} / \mathrm{m}^{2}\right)$} \\
\hline Normal $^{a}$ & $53(24.7)$ & 1 & \\
\hline Overweight $^{c}$ & 39 (38.6) & $1.9(1.2-3.2)$ & $1.5(0.8-2.9)$ \\
\hline Obesity $^{d}$ & $15(40.5)$ & $2.1(1-4.3)$ & $1.4(0.6-3.6)$ \\
\hline \multicolumn{4}{|l|}{ Blood pressure $(\mathrm{mmHg})$} \\
\hline Normal $^{x}$ & $52(21.1)$ & 1 & \\
\hline Pre-hypertensive ${ }^{y}$ & $29(33.0)$ & $1.8(1.1-3.2)$ & $1.2(0.6-2.2)$ \\
\hline Hypertensive ${ }^{z}$ & $32(68.1)$ & $8.0(4-15.8)$ & $2.6(1.1-6.4)^{*}$ \\
\hline \multicolumn{4}{|l|}{ Blood sugar level (mmol/L) } \\
\hline Normal $^{k}$ & $95(26.8)$ & 1 & \\
\hline Prediabetes'/Diabetes $^{\mathrm{m}}$ & $18(66.7)$ & $5.5(2.4-12.6)$ & $2.5(0.9-6.6)$ \\
\hline
\end{tabular}

Adjusted for Age, Tobacco use, Body mass index, Blood pressure and Blood sugar level

CI Confidence interval, $C O R$ Crude odds ratio, aOR Adjusted odds ratio, ED Erectile dysfunction *statistically significant

a $18.5-24.9 \mathrm{~kg} / \mathrm{m}^{2},{ }^{c} 25-29.9 \mathrm{~kg} / \mathrm{m}^{2},{ }^{\mathrm{d}} \geq 30 \mathrm{~kg} / \mathrm{m}^{2}$

${ }^{x}<120 / 80 \mathrm{mmHg},{ }^{y} 120-139 / 89-89 \mathrm{mmHg},{ }^{2} \geq 140 / \geq 90 \mathrm{mmHg}$

${ }^{k}<7.8 \mathrm{mmol} / \mathrm{L},{ }^{\prime}{ }^{\prime} 7.8-11 \mathrm{mmol} / \mathrm{L},{ }^{\mathrm{m}} \geq 11.1 \mathrm{mmol} / \mathrm{L}$

\section{Discussion}

In this study, 29.7\% adult men had ED. Of those with ED, 12.3 and $9.7 \%$ respectively had moderate to severe form. Age and high blood pressure were independent predictors of ED in this setting.

The prevalence of ED in our setting (29.7\%) is slightly higher than prevalence observed in Dar es salaam, Tanzania (24\%), which also used the international index of erectile function five item version (IIEF-5) scale [12]. The results differ from other-community based study conducted in Southwest Nigeria where prevalence of $48-58.9 \%$ was reported by different studies conducted among men aged 30 to 80 years by using international index of erectile function (IIEF) scale [2, 10]. In Egypt, the ED prevalence of $13.4 \%$ was obtained using two questions scale on initiation and maintenance of 
erection for satisfactory sexual intercourse [4]. Differences in age of populations studied, tools in assessing ED and background occurrence of co-morbidities like $\mathrm{DM}$ and hypertension may explain the different prevalence observed in SSA studies. However, having one in three men with ED is a serious problem and calls for countries like Tanzania to start investing in men's sexual and reproductive health in order to achieve the MDG 3 of having healthy lives by 2030 .

Age was strongly associated with ED. Our study showed that individuals aged $40-54$ and $\geq 55$ had higher odds of having ED compared to younger participants aged 18-39 years. Age was also a strong predictor of ED in Ethiopian study where men who aged 40-59 were 6.5 more likely to develop ED and those aged 60 years and above were 7 times more likely to have ED compare to those aged 18-30 years [15]. In spite of comorbidities associated with age, there is decrease in sexual function among men as they age which explains the higher prevalence of ED [16].

The association between smoking and ED had been well established by other authors. The likelihood of having ED was shown even to increase with dose response [17]. Our results are contrary to others as tobacco users had $70 \%$ increased chances of having ED compared to non-tobacco users in bivariate but not in multivariate analysis. Researchers have shown that the effect of smoking in erectile dysfunction is through its impact on vascular morphology and physiology and that withdrawal can reverse the damage [18]. We couldn't find an association of ED and smoking after adjusting for other factors since we had a small proportion of smoker. However, our results are similar to those of Ahmed et al. [19] which showed no association between Tobacco usage and ED after adjusting for confounders [19].

Individuals with diabetes mellitus had higher odds for ED compared to non-diabetic individuals in bivariate but not in multivariate analysis. Results from an Egyptian study done by Zedan et al. [20] reported diabetic individuals had 5 times higher odds of having ED. Also, a study done by Oyelade in Nigeria showed diabetic individuals were 8 times more likely to develop ED [2]. Other studies have shown that diabetic individuals present with ED at a younger age than non-diabetic ones [20]. Diabetes affects vascular system, and this may explain the association with ED. However, lack of association between DM and ED after controlling for confounders in this study may be due to relatively young population (mean age of 39.6 years and very few participants with DM).

In our study participants who were hypertensive had more than 2.6 times higher odds of ED compares to normotensive ones. A study done in west Nigeria also has shown hypertensive individual had a higher prevalence of ED (75\%) compared to normal-tensive (56.9\%) [11]. Hypertension men have disturbance in vascular endothelia which lead to increase in contraction of vascular smooth muscles [21]. However, some drugs that are used for hypertension management can result into ED [21]. Many men have difficulty in admitting they have ED, and this maybe, worse in African society where masculinity is a norm. As a result, many may stop taking antihypertensive medication, resulting in worse complications like stroke. In many sub Saharan Africa countries including Tanzania, hypertension is becoming a sizeable public health problem [22], hence addressing ED in screening and care services for hypertension is needed to improve adherence to management and overall quality of life.

\section{Study strengths and limitations}

This was a community-based study where participants were selected using probability sampling. The results can be generalized to other men in the municipality. There are limitations also that has to be taken into account when interpreting the results of this study. As a cross-sectional study it is difficult to determine temporal relationship. Men are shy to report problems related to sexual performance, and the tool used to measure ED relied on report from men themselves hence under reporting may have led to underestimation of prevalence of ED. RBG was measured on a single point, and those with impaired RBG advised to go for FBG measurement at nearest facility. This could have underestimate, the results of blood glucose. Use of ward and street leaders in informing the men about the study may have introduced bias. Some men could have thought this is related to government and thus not ready to reveal their experiences related to reproductive health and did not participate. But because total number of men aged 18 and above is not known in selected wards, its, difficult to estimate the direction of bias.

\section{Conclusion and recommendations}

The prevalence of ED is high among men in Moshi municipal as 1 out of 3 men have ED. Age and hypertension were independent predictors of ED. These results point to the need of community awareness and education programs to raise awareness among men about existence of ED problem, its consequence and where they can get advice and care in this setting. Further, health providers taking care of hypertensive and men with DM should be equipped with knowledge and skills on early detection for ED and how to counsel and where to refer patients for help. Given that the problem is substantial, there is a need for future studies (qualitative) to explore understanding and effect of ED on men's mental health and quality of life. 


\section{Abbreviations}

BMI: Body Mass Index; BP: Blood pressure; CVD: Cardiovascular Diseases; DM: Diabetes Mellitus; ED: Erectile Dysfunction; HTN: Hypertension; KCMUCo: Kilimanjaro Christian Medical University College; KDC: Kilimanjaro District Council; NCDs: Non-Communicable diseases; RBG: Random Blood Glucose; SDGs: Sustainable Development Goals; SPSS: Statistical Package for Social Sciences; SSA: Sub Saharan Africa; WHO: World Health Organization

\section{Acknowledgements}

We are grateful to men who participated in this study. We also thank the district health management team for permission to conduct the study in the district. The authors are indebted to District Medical Officer of Moshi municipal, Dr. Linda P. Samu as well as ward leaders who helped during interviews.

\section{Authors' contributions}

$\mathrm{KN}, \mathrm{EHM}$ and EM designed the study, carried out statistical analysis and manuscript writing. SM, BJL and OM provided guidance in designing the study, guided in conducting the study, statistical analysis and reviewed the manuscript for intellectual content. The authors read and approved the final manuscript.

\section{Funding}

Tanzania Higher Education Students Loans Board (HESLB) supported Kenan B Nyalile, Emmanuel HP Mushi, and Epiphania Moshi. Sia E. Msuya and Beatrice J. Leyaro were THRiVE-2 faculty and partially supported by the DELTAS Africa Initiative grant \# DEL-15-011 to THRiVE-2.

The funders did not have any role or influence the design of the study, data collection, analysis or interpretation of the results and in development of the manuscript.

\section{Availability of data and materials}

The datasets used and analyzed during the current study can be freely available from the corresponding author on reasonable request.

\section{Ethics approval and consent to participate}

This study was approved by the Kilimanjaro Christian Medical University College (KCMUCo) institution ethical review board (Certificate number UG 007). Permission to conduct the study was sought from the District Medical Officer of Moshi municipal. Purpose of the study, benefit, right to refuse participation or leaving the study was explained to each participant before the interviews. The study participants were informed that the data will be kept confidential and only numbers were used in the questionnaires and not personal identifiers. A signed consent was obtained from each participant. In the case of illiterate men, the right thumbprint was used as a signature.

\section{Consent for publication}

Not applicable, the manuscript does not contain any individual personal data.

\section{Competing interests}

The authors declared that they have no competing interests.

\section{Author details}

${ }^{1}$ Institute of Public Health, Department of Community Health, Kilimanjaro Christian Medical University College (KCMUCo), Po Box 2240, Moshi, Tanzania. ${ }^{2}$ Institute of Public Health, Department of Epidemiology \& Biostatistics, Kilimanjaro Christian Medical University College (KCMUCo), Moshi, Tanzania. ${ }^{3}$ Department of Community Health, Kilimanjaro Christian Medical Centre (KCMC), Moshi, Tanzania. ${ }^{4}$ Department of Urology, KCMUCo \& Kilimanjaro Christian Medical Centre (KCMC), Moshi, Tanzania.

\section{Received: 18 March 2020 Accepted: 23 November 2020}

Published online: 02 December 2020

\section{References}

1. Segraves RT. Considerations for diagnostic criteria for erectile dysfunction in DSM V. J Sex Med. 2010;7(2 Pt 1):654-60. https://doi.org/10.1111/j.17436109.2009.01684.x PMID:20492414.
2. Oyelade BO, Jemilohun CJ, Aderibigbe AA. Prevalence of erectile dysfunction and possible risk factors among men of South- Western Nigeria: a population based study. Pan Afr Med J. 2016;24(124):1-8.

3. Seyam RM, Albakry A, Ghobish A, Arif H, Dandash K, Rashwan H. Prevalence of erectile dysfunction and its correlates in Egypt: a community-based study prevalence of erectile dysfunction and its correlates in Egypt: a communitybased study. Int J Impot Res. 2003;15:237-45.

4. Mutagaywa RK, Lutale J, Aboud M, Kamala BA. Prevalence of erectile dysfunction and associated factors among diabetic men attending diabetic clinic at Muhimbili National Hospital in Dar-es-salaam, Tanzania. Pan Afr Med J. 2014:17(227):1-8.

5. Safarinejad MR. Prevalence and risk factors for erectile dysfunction in a population-based study in Iran. Int J Impot Res. 2003;15:246-52.

6. Idung AU, Abasiubong F, Ukott IA, Udoh SB, Unadike BC. Prevalence and risk factors of erectile dysfunction in Niger delta region, Nigeria. Afr Health Sci. 2012;12(2):160-5.

7. Rajkumar PR, Kumaran KA. Depression and anxiety in men with sexual dysfunction: a retrospective study. Compr Psychiatry. 2015;60:114-8.

8. Liu Q, Zhang Y, Wang J, Li S, Cheng Y, Guo J, et al. Erectile dysfunction and depression: a systematic review and meta analysis. J Sex Med. 2018;15(8):1073-82.

9. Amidu N, Owiredu W, Woode E, Addai-Mensah O, Gyasi-Sarpong K, Alhassan A. Prevalence of male sexual dysfunction among Ghanaian populace: myth or reality ? Int J Impot Res. 2010;22(6):337-42.

10. Olugbengha-Bello Al, Adeoye OA, Adeomi AA, Olajide AO. Prevalence of erectile dysfunction (ED) and its risk factors among adult men in a Nigerian community. Niger Postgrad Med J. 2013;20(2):130-5.

11. Fafiolu AS, Adebayo AM, Akande TO, Akinboboye OO. Erectile dysfunction among male Hypertensives in a tertiary health Facility in South-West Nigeria. Global J Health Sci. 2014;7(1):154-60.

12. Pallangyo $P$, Nicholaus $P$, Kisenge $P$, Mayala $H$, Swai N, Janab M. A community-based study on prevalence and correlates of erectile dysfunction among Kinondoni District residents, Dar Es Salaam, Tanzania. Reprod Health. 2016:13(1):140.

13. Latini DM, Penson DF, Colwell HH, Lubeck DP, Mehta SS, Henning JM, et al. Psychological impact of erectile dysfunction: validation of a new health related quality of life measure for patients with erectile dysfunction. J Urol. 2002:168(5):2086-91.

14. Ministry of Health, Community Development, Gender, Elderly and Children (MoHCDGEC). The National Road map Strategic Plan to Improve Reproductive, maternal, newborn, Child \& Adolescent Health in Tanzania (2016 - 2020). Dar es Salaam; 2016. [cited 2020 May 18]. Available from: https:/www. globalfinancingfacility.org/sites/gff_new/files/Tanzania_One_Plan_ll.pdf.

15. Walle B, Lebeta KR, Fita YD, Abdissa HG. Prevalence of erectile dysfunction and associated factors among diabetic men attending the diabetic clinic at Felege Hiwot referral hospital, Bahil Dar, north West Ethiopia, 2016. BMC Res Notes. 2018;11(1):130.

16. McVary KT, Carrier S, Wessells $\mathrm{H}$. Subcommittee on smoking and erectile dysfunction socioeconomic committee, Sexual Medicine Society of North America. Smoking and erectile dysfunction: evidence based analysis. J Urol. 2001:166(5):1624-32.

17. Millet C, Wen LM, Rissel C, Smith A, Ritchers GA, et al. Smoking and erectile dysfunction: findings from a representative sample of Australian men. Tob Control. 2006:15(2):136-9.

18. Messner B, Bernhard D. Smoking and cardiovascular disease mechanism of endothelial dysfunction and early Atherogenesis. Arterioscler Thromb Vasc Biol. 2014;34(3):509-15

19. Ahmed A, Alnaama A, Shams K, Salem M. Prevalence and risk factors of erectile dysfunction among patients attending primary health care centres in Qatar. East Mediterr Health J. 2011;17(7):587-92.

20. Zedan H, Hareadei AA, Abd-Elsayed AA, Abdel-Maguid EM. Cigarette smoking, hypertension and diabetes mellitus as risk factors for erectile dysfunction in upper Egypt. East Mediterr Health J. 2010;16:281-5.

21. Nunes KP, Labazi H, Webb RC. New insight into hypertension-associated erectile dysfunction. Curr Opin Nephrol Hypertens. 2012;21(2):163-70.

22. Galson SW, Straton CA, Karia F, Kilonzo K, Lunyea J, Patel UD, et al. Epidemiology of hypertension in northern Tanzania: a community-based mixed methods study. BMJ Open. 2017;7(11):e018829.

\section{Publisher's Note}

Springer Nature remains neutral with regard to jurisdictional claims in published maps and institutional affiliations. 